\title{
ASPECTOS CONTÁBEIS DO CRÉDITO DE CARBONO EM UMA EMPRESA PRODUTORA DE ENERGIA LIMPA
}

\author{
ACCOUNTING ASPECTS OF CARBON CREDIT IN A CLEAN ENERGY \\ PRODUCTION COMPANY
}

\author{
André Folster \\ andrefolsterr@gmail.com \\ UFSC
}

\author{
Luiz Felipe Ferreira \\ luizff@cse.ufsc.br \\ UFSC
}

\begin{abstract}
Resumo
Este artigo tem como objetivo investigar a contabilização das negociações dos créditos de carbono na empresa Lages Bioenergética Ltda, nos anos de 2007 a 2011. A pesquisa caracteriza-se como sendo estudo de caso de caráter exploratório com abordagem qualitativa. Os resultados demonstraram que (i) a Lages obtém crédito de carbono por ser uma receita adicional, além de contribuir para a imagem da empresa; (ii) a aquisição do crédito de carbono passa por um longo processo de projeção e análise e profissionais da área formulam o projeto de MDL; (iii) a receita é reconhecida pelos recebimento dos créditos e os custos lançados no exercício em que ocorrem. A Lages Bioenergética faz o reconhecimento das negociações com o crédito de carbono no momento em que elas ocorrem. Desta forma, não incorre ao erro ao demonstrar valores arbitrários em seus demonstrativos, já que não há uma regulamentação própria para negociações deste instrumento.
\end{abstract}

Palavras-chaves: Crédito de Carbono, Tratamento Contábil, Mecanismo de Desenvolvimento Limpo.

\section{Abstract}

This article aims to investigate the accounting of Certified Emission Reductions (CER) trading in the Company Lages Bioenergética Ltda, among the period of 2007 and 2011. The research was conducted as a exploratory case study, using the qualitative approach . The results show that (i) Lages gets the Certified Emission Reductions as an additional revenue; (ii) the Certified Emission Reductions acquisition has a long process of forecasts and analysis and specialized professionals prepare the MDLproject; (iii) revenue is recognized by the cash entries of credits and the costs are recognized in the period that they occur. Lages Bioenergética recognizes the Certified Emission Reductions trading at the moment that it occurs, this way, it doesn't present any mistakes in disclosing arbitrary amounts in its statements, once there is not a specific regulamentation of trading this instrument.

Keywords: Certified Emission Reductions, Accounting Treatment, Clean Development Mechanism (MDL)

Artigo recebido em: 01.11.2012; Aceito em: 30.01.2013

\section{INTRODUÇÃO}

O agravamento das intempéries naturais provocado pelos gases do efeito estufa (GEE's) ocorre na concepção de Cenamo (2004, p. 1) devido às ações antrópicas, principalmente pela expansão do setor industrial, agrícola e de transportes, pelos quais demandaram grande 
consumo de energia, proveniente da queima de combustíveis fósseis (petróleo, carvão mineral e gás natural), além do desmatamento de novas áreas para ocupação e uso da terra com outras atividades. Isso levou ao mundo, principalmente aos países desenvolvidos (MACIEL et al., 2009), a preocupação com a degradação do meio natural e com a relação Homem X Natureza. Essa preocupação com o meio natural, fez com que países representantes da ONU liderassem discussões sobre medidas que tem por objetivo amenizar o avanço da degradação (BARBIERI, RIBEIRO, 2007). Diante dessa questão, em 1997 foi criado o Protocolo de Quioto, que só entrou em vigor em 2005. Neste ano, 55 países aderiram ao mesmo, sendo que estes representam 55\% das potenciais emissões do planeta (RIBEIRO, 2007). Estes países se comprometeram a reduzir gradativamente suas emissões dos Gases do Efeito Estufa, que dentre eles estão: Dióxido de Carbono (CO2), Metano (CH4), Óxido Nitroso (N2O), Hexafluoreto de Enxofre (SF6), Hidrofluorcarbonos (HFCs) e Perfluorcarbonos (PFCs).

No Protocolo de Quioto ficou estabelecido que para viabilizar tal redução três mecanismos poderão ser utilizados, os quais são: Comércio Internacional de Emissões, Implementação Conjunta e o Mecanismo de Desenvolvimento Limpo. Porém somente um pode ser desfrutado em países subdesenvolvidos, o MDL - Mecanismo de Desenvolvimento Limpo, sendo assim, o único que pode ser utilizado no Brasil (RIBEIRO, 2007).

Os projetos de MDL geram um produto expresso em CO2 equivalente (chamado de Crédito de Carbono), que se converte em Reduções Certificadas de Emissões - RCE's após os seguintes procedimentos: formulação do projeto, confirmação da redução dos GEE's, registro nos órgãos competentes e a emissão das RCE's.

\subsection{TEMA E PROBLEMA}

A implantação do MDL gera uma série de procedimentos como, por exemplo, custos do projeto, "estocagem", negociações de venda, e todos estes, por sua vez, têm a necessidade de serem garantidos por um sistema de informação. Porém, não há tratamentos específicos regulamentados por lei ou por norma, gerando com isso, certa arbitrariedade na forma do reconhecimento contábil.

Devido às atribuições da contabilidade estarem pautadas na confiabilidade e na clareza, é necessário que haja uma regulamentação e que todas as empresas que se beneficiam com os projetos de MDL sigam este regulamento.

Neste contexto, este trabalho tem o objetivo de investigar a contabilização das negociações dos créditos de carbono na Lages Bioenergética Ltda.

Esta pesquisa se justifica por demonstrar como ocorre a contabilização de uma empresa do setor elétrico, nas negociações com o crédito de carbono. A originalidade consiste em não haver na academia um estudo referente às negociações com o crédito de carbono, no mesmo ramo e no qual englobasse a motivação e as formas de contabilização usadas para demonstrarem as mesmas.

\section{REFERÊNCIAL TEÓRICO}

Diversos são os trabalhos que tratam da temática do crédito de carbono destacando Ribeiro (2007), Peleias et al. (2007), Barbieri e Ribeiro (2007), de Maciel et al. (2009), Pereira, Nossa e Nossa (2009) e o de Souza et al. (2010) . Uma parte destes trabalhos aborda os aspectos de aquisição e quais seus benefícios relacionados aos projetos de Mecanismo de Desenvolvimento Limpo (MDL), a outra parcela trata dos efeitos e os aspectos contábeis ligados aos créditos de carbono. Destaca-se aqui, os principais aspectos de cada pesquisa e suas contribuições para a temática em estudo. 
O estudo de Ribeiro (2007) busca identificar as transações e os tratamentos contábeis mais adequados em relação à comercialização dos créditos de carbono. A pesquisa foi realizada com base em três empresas, das quais nenhuma havia negociado os créditos no mercado de títulos e sim diretamente com os interessados. Ainda foi constado que essas empresas reconheceram a venda dos créditos de carbono como uma receita eventual e a contrapartida às disponibilidades.

Já o trabalho de Souza et al. (2010), tem o objetivo de analisar as abordagens contábeis consideradas no reconhecimento dos créditos de carbono pela literatura e o perfil dos projetos de MDL no Brasil, e ainda identificar quem são os maiores compradores e quais os projetos mais negociados. Como resultados da pesquisa os autores verificaram que os projetos de MDL do Brasil são potenciais geradores de créditos de carbono e possuem demanda dos países industrializados, principalmente por projetos do setor energético e suinocultura, dos quais representaram $82 \%$ das compras. Outra observação que os autores constataram foi a não existência de unanimidade quanto ao reconhecimento dos créditos de carbono como ativo intangível, estoque e derivados. Sendo que a tendência em reconhecê-lo é por derivados. Por fim, mencionaram que os resultados apresentados chamam a atenção para a necessidade do pronunciamento de órgãos como a CVM, Receita Federal e Banco Central do Brasil, como também, do CPC e CFC na elaboração de normas contábeis aplacadas aos créditos de carbono.

A pesquisa de Peleias et al. (2007) procura examinar o tratamento contábil que as empresas brasileiras, que desenvolvem projetos de MDL (Mecanismo de Desenvolvimento Limpo), estão aplicando aos créditos de carbono. O trabalho realizado no ano de 2006 pretende ser uma contribuição às discussões dos aspectos contábeis relativos a este tema no Brasil. Para a realização do mesmo, foi enviado um questionário para 109 empresas, que apresentavam projetos registrados ou em fase de registro na UNFCCC (United Nations Framework Convention on Climate Change), das quais somente 16 responderam.

Nesta pesquisa Peleias et al. destaca que de 16 empresas, apenas uma declarou que está efetivamente reconhecendo contabilmente os créditos gerados. Dessa maneira, ela usava o critério de valoração dos estoques antes da transferência, registrando os valores no Ativo circulante e Realizável a longo prazo de acordo com a expectativa de venda a valores de mercado, e a contra partida como receita a realizar. Ainda sobre os resultados da pesquisa, constataram que há opiniões distintas sobre o tratamento contábil aplicável ao Crédito de Carbono, e que é necessária uma ação de regulamentação dos órgãos contábeis ou pelo governo, em razão das questões tributárias.

Os artigos de Barbieri e Ribeiro (2007) e de Pereira, Nossa e Nossa (2009) discutem o reconhecimento da receita. O primeiro discorre que o momento de reconhecimento da receita é o da entrega dos títulos de Reduções Certificadas de Emissões (RCE's) ao comprador. E ainda enquadra essa receita como co-produto, uma vez que é gerada de uma matéria-prima, na mesma matriz produtiva, possui mercado de venda estável e são representativas no futuro da empresa. Já o segundo demonstra três casos de reconhecimento da receita. O primeiro caso seria da venda antecipada, no qual o reconhecimento só ocorre na entrega das RCE's. $\mathrm{O}$ segundo caso seria a venda e a entrega das RCE's, após sua posse, caracterizando assim uma receita. E o terceiro caso seria na conclusão da produção, entendida no trabalho, como o período anual de verificação para a emissão da RCE. Assim o estoque fica avaliado pelo valor de mercado.

Outra pesquisa relacionada ao tema aqui discutido, foi a de Maciel et al. (2009). Nesse trabalho, foram propostas formas de contabilizações que serão demonstradas no decorrer do trabalho e enfatizam o reconhecimento do passivo e de benefícios futuros, como ativos intangíveis, gerados pelos créditos de carbono. E a necessidade de regulamentação por órgãos 
competentes no sentido de padronização também foram relatados, assim como em alguns outros trabalhos.

Dentre esses estudos similares apresentados, pode-se observar maior aproximação com o presente estudo, o trabalho de Maciel et al. (2009), quanto as formas de contabilização; os estudos de Ribeiro (2007) e Peleias et al. (2007), quanto a comparação do reconhecimento da receita em outra empresa; as pesquisas de Barbieri e Ribeiro (2007) e Pereira, Nossa e Nossa (2009) quanto as sugestões de reconhecimento da receita.

Desses trabalhos selecionados, percebe-se a divisão de objetos de estudo. Todos eles procuram discutir as contabilizações nas transações com os créditos de carbono, mas nenhum deles procura discutir todas as transações contidas dentro do processo por inteiro. Deste modo, este trabalho busca contemplar todas essas áreas através de um estudo de caso em uma empresa do setor de energia elétrica que tem projeto registrado junto a ONU.

\subsection{ORIGEM E FINALIDADE DO CRÉDITO DE CARBONO}

O crédito de carbono tem sua origem no Protocolo de Quioto, firmado por 55 países, que formam 55\% das potenciais emissões do planeta. Esse protocolo foi criado em 1997, e entrou em vigor em fevereiro de 2005. Os países que aderiram ao Protocolo se comprometeram em reduzir em 5\% seus níveis de emissões dos gases do efeito estufa, considerando a realidade de 1990. Cada país deve criar os meios e instrumentos legais para que suas empresas cumpram os objetivos e alcancem suas metas (RIBEIRO, 2007).

Segundo Pereira e Nossa (2005), o Protocolo de Quioto foi formulado devido à falta de observância do acordo firmado no Protocolo de Montreal, no qual se previa a voluntária redução gradual das emissões do gás clorofluorcarbono (CFC). Diante disso, a ONU se viu na obrigação de organizar um novo protocolo - Protocolo de Quioto - que veio a tornar as reduções de voluntárias para obrigatórias.

Antes da criação do crédito de carbono pelo Protocolo de Quioto surgiram outras formas parecidas para o mesmo fim. Para Ribeiro (2007), os créditos de carbono surgiram nos países desenvolvidos, como meio de inibir a produção de poluentes. Nesses países, a legislação local estabelecia níveis máximos de emissões de certos gases, e aqueles que emitissem um volume abaixo do estabelecido tinham o direito a títulos de créditos equivalentes à porção reduzida, os quais poderiam ser vendidos.

Existem duas atividades para a obtenção dos Créditos, uma é a diminuição da emissão dos GEE's e a outra é retirar da atmosfera os gases já emitidos. Sob a ótica da sustentabilidade ambiental, a primeira atividade minimiza os efeitos nocivos dos GEE através de processos que não permitem que os gases sejam lançados na atmosfera; já os que retiram são chamados de sequestro de carbono (BUFONI, FERREIRA, 2010).

A finalidade (SILVA JR et al., 2010) do crédito de carbono esta ligado a dois fatores: (i) o primeiro na transferência de tecnologia dos países desenvolvidos para os subdesenvolvidos; (ii) o segundo é a diminuição das emissões dos GEE's. Fazendo dessa forma, que os países subdesenvolvidos continuem crescendo, porém com tecnologias limpas.

Dentre os gases causadores do efeito estufa estão: Dióxido de Carbono (CO2), Metano (CH4), Óxido Nitroso (N2O), Hexafluoreto de Enxofre (SF6), Hidrofluorcarbonos (HFCs) e Perfluorcarbonos (PFCs). Para que ocorresse a redução desses gases de forma gradativa e não de forma brusca, foram criadas metas de redução. Essas metas consistem em um limite de poluição para cada país participante do protocolo, consequentemente, cada empresa terá o seu limite. As empresas que tiverem poluído abaixo do seu limite, poderão vender esse direito, e as empresas que ultrapassarem esse limite, terão que comprar o direito (PEREIRA, NOSSA, NOSSA, 2009). 
Essas negociações dos direitos de poluição ocorrem através dos projetos de MDL Mecanismo de Desenvolvimento Limpo. Esses projetos, segundo Peleias et. al (2007, p. 2), "geram um produto, expresso em $\mathrm{CO} 2$ equivalente (daí a origem do nome Crédito de Carbono), que se converte em Reduções Certificadas de Emissões - RCE's (ou CER Certified Emission Reduction), após a sua emissão e registro". O CO2 equivalente significa a quantidade de quilogramas de carbono correspondente à redução do gás que esta sendo eliminado (PEREIRA, NOSSA, NOSSA, 2009).

Para Ribeiro (2005, apud BARBIERI, RIBEIRO, 2007), as RCEs podem ser consideradas como títulos derivativos por proporcionarem aos agentes econômicos menores exposição ao risco das variações de preços no momento em que estes títulos estiverem em plena negociação, gerando os créditos previstos.

Essas Reduções Certificadas de Emissões são negociadas no mercado de carbono que de acordo com a BM\&F (2012), é um termo popular utilizado para denominar os sistemas de negociação de unidades de redução de emissões de gases de efeito estufa (GEEs). No âmbito do Protocolo de Quioto, há dois tipos de mercado de carbono: mercado de créditos gerados por projetos de redução de emissões (projetos de Mecanismo de Desenvolvimento Limpo e projetos de Implementação Conjunta) e mercado de permissões.

\title{
2.1.1 PAÍSES PRECURSORES DA ATIVIDADE COM CRÉDITO DE CARBONO
}

Antes mesmo do Protocolo de Quioto, já havia negociações para prática do comércio de emissões (ou permissões), merece destaque a Noruega, Austrália e o Reino Unido com seus mercados domésticos. Como exemplo dessas negociações tem-se (ROCHA, 2003):

$\checkmark$ Erupt (emission reduction units purchase tender) um programa do governo holandês que visa estimular a realização dos projetos de implementação conjunta. Cinco projetos foram selecionados em 2000, e seis em 2001, os quais consumiram um bilhão de euros;

$\checkmark$ Emissions Trading Scheme, mercado nacional do Reino Unido;

$\checkmark$ Fundo Protótipo de Carbono do Banco Mundial;

$\checkmark$ BioCarbon Fund do Banco Mundial;

$\checkmark$ Chicago Climate Exchange, programa voluntário nos Estados Unidos;

$\checkmark$ Estrutura de comércio de emissões é um programa da Comunidade Européia, que estabeleceu um mercado voluntário de licenças de emissão de GEEs e do controle das emissões, do qual participavam 34 companhias (FAIRBAIM, 2003, apud RIBEIRO, 2007).

Um exemplo da atual utilização dos créditos esta no setor de transporte.

\begin{abstract}
Ele é responsável por $25 \%$ dos gases que provocam o efeito estufa, mas em Santiago do Chile, especificamente, este percentual aumenta para 33\%. Foi feita uma reestruturação da malha viária e da forma de operação dos serviços, de forma que se evitou a superposição de percursos. Estima-se que os ganhos decorrentes desse projeto sejam da ordem de US\$ 2,9 milhões por ano e que as reduções de CO2, no período de 2006 a 2015, sejam de 3.664.778 toneladas por ano (GIESEN, 2005, p.94 apud., RIBEIRO, 2007, p.6).
\end{abstract}

As empresas que negociam Crédito de Carbono no Brasil estão enquadradas dentro das seguintes atividades: cogeração de energia com biomassa; tratamento de Resíduos Sólidos Urbanos e aproveitamento de biogás em aterros sanitários; substituição de combustíveis e/ou aumento da eficiência energética em processos industriais; instalação de biodigestores para 
captação de metano em granjas de confinamento (particularmente suinocultura); implantação de pequenas centrais hidrelétricas (PCHs); e os projetos de reflorestamento.

\subsubsection{METODOLOGIAS DE CRÉDITO DE CARBONO}

O Protocolo de Quioto, para alcançar o objetivo de redução dos gases do efeito estufa, estabeleceu três mecanismos de flexibilização. Esses mecanismos foram criados para propiciar aos países signatários - do anexo I - opções para atingirem suas metas de redução de emissões. Dessa forma, instituem-se três instrumentos econômicos.

O primeiro é o Comércio Internacional de Emissões, também denominado como Emission Trade, que permite aos países industrializados - do anexo I - a comercialização de até $10 \%$ da redução de suas emissões (PEREIRA, NOSSA, 2005). Admitindo assim, um livre comércio de direitos de redução de emissões em nível global. Comercialização esta amparada pelo artigo 17 do Protocolo de Quioto (FARIAS et al., 2010).

O segundo é a Implementação Conjunta (Joint Implementation - JI), que proporciona aos países do anexo I uma alternativa para adquirir créditos de carbono (FARIAS et al., 2010). Essa alternativa consiste em financiar projetos em outros países, também desenvolvidos, para compensar suas emissões. "Um projeto de energia térmica na Romênia, dirigido por uma entidade Suíça (empresa ou governo), por exemplo, poderia ser enquadrado como projeto de Implementação Conjunta." (PEREIRA, NOSSA, NOSSA, 2009, p. 108)

O terceiro tipo é o Mecanismo de Desenvolvimento Limpo - MDL (Clean Development Mechanism), o qual se refere a créditos gerados por atividades de redução de emissões nos países subdesenvolvidos - países não listados no anexo I - (PEREIRA, NOSSA, NOSSA, 2009), nas quais esses créditos são comprados por empresas de países desenvolvidos.

\subsection{MECANISMO DE DESENVOLVIMENTO LIMPO}

O MDL é o único mecanismo que envolve países desenvolvidos e subdesenvolvidos. Essa relação acontece pois o referido mecanismo permite que os países listados no Anexo I do Protocolo cumpram suas metas de duas formas: de forma direta, pela aquisição de Crédito de Carbono, ou de forma indireta, com investimentos nos países em desenvolvimento que geram créditos via projetos do MDL (PELEIAS, 2007). Com esses créditos, os países desenvolvidos têm seus compromissos de redução de emissões abatidos.

Conforme Rocha (2003, p. 9):

A proposta do MDL consiste em que cada tonelada de $\mathrm{CO} 2$ deixada de ser emitida
ou retirada da atmosfera por um país em desenvolvimento poderá ser negociada no
mercado mundial, criando um novo atrativo para redução das emissões globais. Os
países do Anexo I estabelecerão em seus territórios metas para redução de CO2
junto aos principais emissores. As empresas que não conseguirem (ou não
desejarem) reduzir suas emissões poderão comprar Certificados de Emissões
Reduzidas (CER) em países em desenvolvimento e usá-los para cumprir suas
obrigações.

O objetivo deste mecanismo segundo Farias et al., (2010) é incentivar as Partes pertencentes ao Não-Anexo I da Convenção, para que sejam capazes de viabilizar o desenvolvimento sustentável através da prática de projetos de redução de GEE e, desse modo, colaborarem para o objetivo fim da Convenção. 
Vale ressaltar ainda, que o "Mecanismo de Desenvolvimento Limpo (MDL) nasceu de uma proposta brasileira à Convenção Quadro das Nações Unidas sobre Mudança do Clima" (SCHMITT e PEIXE, 2008).

Para a obtenção desses créditos, é necessário seguir uma série de procedimentos que estão relatados no quadro 1, a seguir:

\begin{tabular}{|c|c|}
\hline Etapas & Definições \\
\hline $\begin{array}{l}\text { Etapa 1: } \\
\text { Preparação de } \\
\text { um projeto MDL } \\
\text { para validação }\end{array}$ & $\begin{array}{l}\text { As entidades promotoras do projeto devem preparar um documento denominado } \\
\text { Documento de Concepção do Projeto (DCP), em inglês, Project Design Document (PDD). } \\
\text { Esse documento deverá ser submetido a uma consulta pública pelo período de } 30 \text { dias e } \\
\text { deve conter as seguintes informações: a) Uma descrição geral do projeto; b) Uma linha de } \\
\text { base calculada a partir de uma metodologia aprovada; c) Uma estimativa do período de vida } \\
\text { e do período de emissão de créditos do projeto; d) Uma demonstração de como o projeto } \\
\text { gera reduções de emissões adicionais; e) Uma analise de impactos ambientais; f) } \\
\text { Apresentação dos resultados da consulta pública efetuada; g) Um plano de monitorização e } \\
\text { averiguação que utiliza uma metodologia de monitorização aprovada. } \\
\text { Deve ser providenciado, ainda, um documento que comprove o interesse de participação } \\
\text { voluntária das partes envolvidas e a confirmação do país hospedeiro da contribuição do } \\
\text { projeto para o desenvolvimento sustentável. } \\
\text { Assim, conforme citado, é obrigatório que a empresa apresente no DCP qual seria a } \\
\text { evolução da emissão de gases de efeito estufa ao longo do tempo, como também, apresente } \\
\text { uma metodologia para o cálculo das emissões, a ser avaliada pelo Painel de Metodologia do } \\
\text { MDL (grupo formado por vários cientistas de diversos países e que dá suporte técnico ao } \\
\text { Conselho Executivo do MDL). Para algumas situações, como para florestamento e o } \\
\text { reflorestamento, já existe uma metodologia definida, mas haverá projetos para os quais a } \\
\text { empresa deverá criar metodologia própria. }\end{array}$ \\
\hline $\begin{array}{l}\text { Etapa 2: } \\
\text { Validação ou } \\
\text { rejeição do } \\
\text { projeto }\end{array}$ & $\begin{array}{l}\text { etapa seguinte é encaminhar o projeto para a Entidade Operacional Designada, } \\
\text { esponsável pela aprovação ou reprovação do projeto. Essa entidade deve ser qualificada e } \\
\text { econhecida pelo Conselho Executivo do MDL e, no Brasil, pela Comissão Interministerial } \\
\text { e Mudanças Globais do Clima - CIMGC. }\end{array}$ \\
\hline $\begin{array}{l}\text { Etapa 3: } \\
\text { Registro pe } \\
\text { Comissão } \\
\text { Executiva }\end{array}$ & $\begin{array}{l}\text { ecebido o relatório de validação, a Comissão Executiva tem oito semanas para aceitar } \\
\text { rmalmente o projeto ou expor suas reservas. Caso se omita nesse prazo, e ao menos que } \\
\text { m dos países envolvidos no projeto ou pelo menos três membros da Comissão Executiva } \\
\text { xijam revisão, o projeto é registrado automaticamente, passando-se a etapa seguinte. }\end{array}$ \\
\hline $\begin{array}{l}\text { Etapa 4: } \\
\text { Verificação, } \\
\text { Certificação e } \\
\text { Emissão de CRE }\end{array}$ & $\begin{array}{l}\text { Depois de registrado o projeto, os interessados devem monitorar a redução de emissões, em } \\
\text { conformidade com o plano apresentando no PDD. Deverá contratar, então, outra Entidade } \\
\text { Operacional Designada, para aferir as reduções de emissão e preparar relatório de } \\
\text { verificação. Esse relatório é, então, remetido à Comissão Executiva, que, caso o aprove, } \\
\text { deverá certificar a redução de emissões, emitindo um CRE para cada tonelada de CO2 (ou } \\
\text { valor equivalente de outros gases estufa) cujo sequestro se verificou. Esse procedimento } \\
\text { deverá de repetir durante todo o período de crédito do projeto. }\end{array}$ \\
\hline
\end{tabular}

Quadro 1: Etapas do processo de realizações de um projeto MDL

Fonte: Maciel et al., 2009, p. 98 - 99

Os créditos gerados por meio deste mecanismo têm sua medição em unidades de redução de emissões, dos quais se chamam de Reduções Certificadas de Emissões (RCE) (CRUZ, PAULINO, 2010).

\subsection{CONTABILIZAÇÃO DAS OPERAÇÕES COM CRÉDITO DE CARBONO}

Verifica-se hoje uma diversidade de negociações com crédito de carbono, cada um com suas inovações tecnológicas ou aquisições de tecnologias diferentes que agridam menos o meio ambiente. Com isso gera-se a necessidade de contabilização destas operações, porém não existe uma regulamentação por parte dos órgãos contábeis e da Comissão de Valores 
Mobiliários (CVM) que discipline como deverá ocorrer a contabilização destas operações e que momento reconhecer os créditos de carbono na contabilidade das empresas envolvidas (MACIEL et al., 2009). A realidade é que mesmo sem a normatização necessária, as operações ocorrem e necessitam de registros contábeis.

As contabilizações relacionadas aos créditos de carbono vêm sendo muito discutida. Discutise o enquadramento ideal para sua natureza; como seus custos devem ser contabilizados, e em que momento deve ser reconhecido sua receita. O quadro 2 faz uma comparação entre Valores mobiliários - derivativos, Intangível e Commodities.

\begin{tabular}{|c|c|c|}
\hline Valores Mobiliários - Derivativos & Intangível & Commodities \\
\hline Ativo-base. & Benefícios Futuros & Mercadoria padronizada. \\
\hline $\begin{array}{l}\text { A não existência } \text { ou } \\
\text { investimento inicial. }\end{array}$ & $\begin{array}{l}\text { Gerados internamente: difícil } \\
\text { determinação dos custos }\end{array}$ & $\begin{array}{l}\text { Pequeno grau } \\
\text { industrialização } \\
\text { beneficiamento. }\end{array}$ \\
\hline $\begin{array}{l}\text { Associado ao risco de oscilações de } \\
\text { preços. }\end{array}$ & $\begin{array}{l}\text { Normalmente reconhecidos } \\
\text { quando adquiridos de } \\
\text { terceiros. }\end{array}$ & $\begin{array}{l}\text { Produzidos em escala } \\
\text { mundial. }\end{array}$ \\
\hline Liquidação em data futura. & $\begin{array}{l}\text { Dificuldade em compará-los } \\
\text { ao valor de mercado. }\end{array}$ & $\begin{array}{llr}\text { Mercado } & \text { de } & \text { derivativos } \\
\text { voltados } & \text { aos } & \text { contratos } \\
\text { futuros. } & & \\
\end{array}$ \\
\hline $\begin{array}{l}\text { Valor das transações } \\
\text { comportamento futuro } \\
\text { ceriva do outros } \\
\text { mercados. }\end{array}$ & Incerteza. & \\
\hline
\end{tabular}

Quadro2: Principais Características sobre a natureza das definições sobre RCEs.

Fonte: Muniz (2008 apud BUFONI, FERREIRA, 2010, p. 10)

Bufoni e Ferreira (2010, p. 10) entendem que os certificados não se enquadram totalmente em nenhuma das opções apresentadas. Relatam que:

[e]m relação a derivativos, pode-se dizer que as RCEs não estão associadas a risco de oscilação de preços no mercado do ativo original; quanto a commodities, atuam no mercado dos contratos futuros e mesmo equivalendo a toneladas de $\mathrm{CO} 2$, as atividades geradoras dos certificados não são padronizadas; e como intangível tornase ainda mais difícil essa classificação, dado que carbono tem massa, é medido em toneladas e atenderia apenas à característica de "benefícios futuros" que atende as RCEs.

Quanto à contabilização dos créditos, na revisão de literatura foram encontradas algumas sugestões. No quadro 3 seguem sugestões de tratamentos contábeis em ordem cronológica e por autor. Primeiro para empresas que fornecem os créditos de carbono, que é o caso das empresas situadas no Brasil e consequentemente da empresa em estudo.

\begin{tabular}{|l|l|l|}
\hline \multicolumn{3}{|c|}{ Empresas que desenvolvem projetos de MDL } \\
\hline \multicolumn{1}{|c|}{ Evento } & \multicolumn{1}{|c|}{ Lançamento } & \multicolumn{1}{|c|}{ Autor } \\
\hline $\begin{array}{l}\text { Reconhecimento da } \\
\text { receita (Venda } \\
\text { antecipada) }\end{array}$ & Débito - Adiantamento por conta do crédito de carbono a realizar & $\begin{array}{l}\text { Pereira e } \\
\text { Nossa (2005) } \\
\text { Crédito - Receita de vendas provenientes de crédito de carbono }\end{array}$ \\
\hline Ativação dos custos & $\begin{array}{l}\text { Débito - Estoque de produtos - Madeira custos de plantação, manutenção } \\
\text { e manejo - Madeira R\$ 12.000,00 } \\
\text { Débito - Estoque de produtos - Carbono custos incrementais de manejo e e } \\
\text { certificação - Carbono R\$ 8.000,00 }\end{array}$ & $\begin{array}{l}\text { Fufoni, } \\
\text { Mues e } \\
\text { Muniz }\end{array}$ \\
\hline
\end{tabular}




\begin{tabular}{|c|c|c|}
\hline & Crédito - Caixa R $\$ 20.000,00$ & $(2007)$ \\
\hline Emissão de títulos & $\begin{array}{l}\text { Débito - Estoque de carbono certificado } \mathrm{R} \$ 10.000,00 \\
\text { Crédito - Estoque de produtos - Carbono } \mathrm{R} \$ 8.000,00 \\
\text { Crédito - Ganhos não realizados (PL) R\$2.000,00 }\end{array}$ & $\begin{array}{l}\text { Ferreira, } \\
\text { Bufoni, } \\
\text { Marques e } \\
\text { Muniz } \\
(2007)\end{array}$ \\
\hline Venda dos títulos & $\begin{array}{l}\text { Débito - Caixa } \mathrm{R} \$ 10.000,00 \\
\text { Crédito - Receita créditos de carbono } \mathrm{R} \$ 10.000,00 \\
\text { Débito - Ganhos não realizados (PL) R } \$ 2.000,00 \\
\text { Crédito - Estoque de carbono certificado R } \$ 2.000,00 \\
\text { Débito - Custo de carbono vendido R } \$ 8.000,00 \\
\text { Crédito - Estoque de carbono certificado R } \$ 8.000,00\end{array}$ & $\begin{array}{l}\text { Ferreira, } \\
\text { Bufoni, } \\
\text { Marques e } \\
\text { Muniz } \\
(2007)\end{array}$ \\
\hline $\begin{array}{l}\text { Expectativa / Início } \\
\text { do Projeto }\end{array}$ & $\begin{array}{l}\text { Débito - Ativo Intangível sobre a expectativa do projeto MDL } \\
\text { Crédito - Disponibilidades }\end{array}$ & $\begin{array}{l}\text { Maciel et al., } \\
(2009)\end{array}$ \\
\hline $\begin{array}{l}\text { Venda da } \\
\text { Expectativa }\end{array}$ & $\begin{array}{l}\text { Débito - Disponibilidade } \\
\text { Crédito - Obrigação para Empresa }\end{array}$ & $\begin{array}{l}\text { Maciel et al., } \\
(2009)\end{array}$ \\
\hline $\begin{array}{l}\text { Confirmação da } \\
\text { Expectativa - } \\
\text { Seqüestro de CO2 }\end{array}$ & $\begin{array}{l}\text { Débito - Estoque de Créditos de Carbono Certificado } \\
\text { Crédito - Investimento - Ativo Intangível s/ a expectativa do projeto }\end{array}$ & $\begin{array}{l}\text { Maciel et al., } \\
(2009)\end{array}$ \\
\hline $\begin{array}{l}\text { Entrega do Crédito } \\
\text { a empresa } \\
\text { compradora ou } \\
\text { financiadora }\end{array}$ & $\begin{array}{l}\text { Débito - Obrigação para Empresa } \\
\text { Crédito - Estoque de Créditos de Carbono Certificado }\end{array}$ & $\begin{array}{l}\text { Maciel et al., } \\
(2009)\end{array}$ \\
\hline \multicolumn{3}{|c|}{ Empresas compradoras de Crédito de Carbono } \\
\hline Evento & Lançamento & Autor \\
\hline $\begin{array}{l}\text { Compra para } \\
\text { mercado de ações }\end{array}$ & $\begin{array}{l}\text { Débito - Investimentos temporários ambientais - Créditos de carbono } \\
\text { Crédito - Disponibilidade }\end{array}$ & $\begin{array}{l}\text { Tasso e } \\
\text { Nascimento } \\
(2005)\end{array}$ \\
\hline $\begin{array}{l}\text { Compra para } \\
\text { reserva futura, para } \\
\text { cumprimento das } \\
\text { quotas }\end{array}$ & $\begin{array}{l}\text { Débito - Ativo permanente - Investimentos ambientais - Créditos de } \\
\text { carbono } \\
\text { Crédito - Disponibilidade }\end{array}$ & $\begin{array}{l}\text { Tasso e } \\
\text { Nascimento } \\
(2005)\end{array}$ \\
\hline $\begin{array}{l}\text { Contabilização no } \\
\text { recebimento de } \\
\text { Quotas }\end{array}$ & $\begin{array}{l}\text { Débito - Ativo circulante - Direitos ambientais realizáveis (Certificados } \\
\text { de carbono) - Bônus } \\
\text { Crédito - Passivo circulante - Obrigações ambientais (Quotas de } \\
\text { carbono) }\end{array}$ & $\begin{array}{l}\text { Tasso e } \\
\text { Nascimento } \\
(2005)\end{array}$ \\
\hline $\begin{array}{l}\text { Para obtenção do } \\
\text { direito de venda de } \\
\text { crédito ou da } \\
\text { necessidade de } \\
\text { compra de crédito } \\
\text { ao final de cada } \\
\text { período que será } \\
\text { determinado }\end{array}$ & $\begin{array}{l}\text { Débito - Passivo circulante - Obrigações ambientais (Quotas de carbono) } \\
\text { Crédito - Ativo circulante - Direitos ambientais realizáveis (Certificados } \\
\text { de carbono) - Bônus }\end{array}$ & $\begin{array}{l}\text { Tasso e } \\
\text { Nascimento } \\
(2005)\end{array}$ \\
\hline $\begin{array}{l}\text { Recebimento da } \\
\text { Meta de } \\
\text { redução }\end{array}$ & $\begin{array}{l}\text { Débito - Custo } \\
\text { Crédito - Obrigações em Reduzir a Emissão }\end{array}$ & $\begin{array}{l}\text { Maciel et al., } \\
(2009)\end{array}$ \\
\hline $\begin{array}{l}\text { Compra da } \\
\text { Expectativa / } \\
\text { Financiamento do } \\
\text { Projeto }\end{array}$ & $\begin{array}{l}\text { Débito - Investimentos - Ativo Intangível } \\
\text { Crédito - Disponibilidades }\end{array}$ & $\begin{array}{l}\text { Maciel et al., } \\
\text { (2009) }\end{array}$ \\
\hline $\begin{array}{l}\text { Recebimento dos } \\
\text { Créditos }\end{array}$ & $\begin{array}{l}\text { Débito - Estoques Créditos de Gases de Efeito Estufa } \\
\text { Crédito - Investimentos - Ativo Intangível }\end{array}$ & $\begin{array}{l}\text { Maciel et al., } \\
(2009)\end{array}$ \\
\hline
\end{tabular}


\begin{tabular}{|l|l|l|}
$\begin{array}{l}\text { Utilização dos } \\
\text { Créditos } \\
\text { Adquiridos }\end{array}$ & $\begin{array}{l}\text { Crédito }- \text { Estoques } \\
\text { Débito }- \text { Obrigações em Redução de Emissões }\end{array}$ & $\begin{array}{l}\text { Maciel } \text { et al., } \\
\text { (2009) }\end{array}$ \\
\hline
\end{tabular}

Quadro 3: Tratamento contábil de projetos de MDL

Fonte: Dados da pesquisa

Para Pereira e Nossa (2005) na fase de concepção e de implantação do projeto são realizados despesas pré-operacionais, mas, estes ainda não realizaram seus objetivos, portanto, ainda existe um grau de incerteza quanto à obtenção dos RCE's. Sendo assim, não é o momento para se reconhecer a receita.

Os autores acima referenciados consideram que depois de emitida a certificação é possível o reconhecimento da receita oriunda da venda dos créditos de carbono. Pois nesse momento são atendidas as condições necessárias que são: realização de todo ou quase todo o esforço para que se gere a receita; os custos e as despesas sejam reconhecidos; e seja possível a validação econômica pelo mercado, dada a redução das incertezas quanto à obtenção das RCE's.

Segundo Pereira e Nossa (2005), a estocagem das RCE's é o ponto em que o valor de mercado é prontamente determinável, e o risco da não-venda é praticamente nulo, possibilitando, à luz da teoria da contabilidade, o reconhecimento da receita antes do ponto de transferência ao cliente, sendo assim, o estoque fica avaliado no final de cada período, pelo preço de venda naquele momento.

A respeito de como devem ser consideradas as vendas dos créditos de carbono, Tasso e Nascimento (2005) citam que poderão ser receitas ambientais, já que os créditos originam-se do cumprimento das metas regulamentadas no protocolo de Quioto.

Por se tratar de um mercado novo e que movimenta muito dinheiro as contabilizações dessas negociações devem ser levadas a sério. Como vimos nesse tópico, muitos autores citam seus modos de ver as negociações. E isso também vem ocorrendo com as empresas, já que as particularidades das negociações são muito grandes.

É importante que haja confiabilidade nas informações contábeis e clareza (MACIEL et al., 2009). Portanto, há que se ter o reconhecimento do passivo gerado pelas emissões de carbono e reconhecimento de benefícios futuros gerados pelos créditos como ativos intangíveis. E para que haja estes, é necessária uma adequação as Normas Contábeis, por meio do Conselho Federal de Contabilidade, no sentido de padronizar o tratamento e a evidenciação, obtendo assim, informações mais reais.

Conforme Barbieri e Ribeiro (2007), essas negociações de crédito de carbono podem afetar significativamente a estrutura patrimonial da empresa, e isto deve estar devidamente registrado na contabilidade. E para que isso ocorra, é necessário preparo e normatização.

\section{METODOLOGIA DA PESQUISA}

A pesquisa em questão caracteriza-se, quanto à natureza metodológica, como exploratória (VIEIRA, 2002) por buscar os procedimentos de contabilização do crédito de carbono em uma empresa real. Por esta pesquisa ter o intuito de aprofundar o conhecimento nas operações de contabilização do crédito de carbono, esse estudo caracteriza-se como indutivo (LAKATOS; MARCONI, 1991) quanto à lógica de pesquisa.

Para coleta de dados deste trabalho serão utilizados dados primários (RICHARDSON, 1999). Caracterizando-se como análise documental, pois conforme Gil (2007) é considerado fonte documental "quando material consultado é interno à organização".

Em relação ao problema de pesquisa, será examinado e refletido como a empresa faz sua contabilização em relação aos créditos de carbono, com isso a abordagem se caracteriza como 
qualitativa (RICHARDSON, 1999). O procedimento técnico utilizado para essa pesquisa foi o estudo de caso, que segundo Yin (2005), "é uma investigação empírica que investiga um fenômeno contemporâneo dentro de seu contexto da vida real, especialmente quando os limites entre o fenômeno e o contexto não estão claramente definidos". Sendo assim, esta pesquisa estuda as formas de contabilização que a Lages Bioenergética Ltda. utiliza em seus procedimentos.

\subsection{PROCEDIMENTO PARA COLETA E ANÁLISE DOS DADOS}

A base principal de coleta de dados foi a aplicação de uma entrevista semi- estruturada, na qual o entrevistado foi o responsável pelo desenvolvimento do projeto de MDL da Lages Bioenergética, sendo ele do setor de Desenvolvimento de Negócios. A entrevista foi composta de 7 questões que foram utilizadas para alcançar os objetos específicos. Para complementar, foi realizada uma conversa informal via e-mail com os responsáveis da área contábil.

As questões 1 e 3 buscam identificar os interesses que a empresa tem em ter os créditos de carbono, saber quais são as principais motivações que levam a empresa implantar o MDL, na qual a questão 2 foi formulada para identificar quais são os benefícios em obter os créditos além da receita gerada. Todas essas perguntas serão analisadas de forma separada, e será formulado um texto para que se possa transmitir fielmente as opiniões e visões da empresa.

A questão 4 questiona qual a formação dos profissionais envolvidos na formulação do projeto de obtenção das Reduções Certificadas de Emissões - RCE's. Em complemento aos profissionais se questiona com a questão 5 se foi necessário algum tipo de consultoria e quais os pontos de análise desses consultores.

A questão 6 foi formulada para identificar quais são as etapas da obtenção do MDL. Por fim, na questão 7 questiona-se quais os órgãos envolvidos em todo o processo, da criação do projeto até sua permissão final e fiscalização.

A conversa informal com os responsáveis pela contabilidade foi realizada no intuito de chegarmos à informação sobre as contabilizações e entendimentos deles quanto a essas negociações. Tendo como foco, saber sobre a aquisição dos certificados de redução, o seu suposto armazenamento e como ocorre a contabilização da venda dos mesmos. E para encontrar outras questões sobre a empresa foram pesquisadas via internet assuntos relacionados aos créditos de carbono vendidos pela empresa.

\section{APRESENTAÇÃO DA EMPRESA LAGES BIOENERGÉTICA LTDA.}

A empresa Lages Bioenergética Ltda. (Lages ou Sociedade), com sede no município de Lages, Estado de Santa Catarina (SC), foi constituída em 26.06.2002 com o objetivo de construir, operar e manter unidades de co-geração de energia elétrica e vapor, bem como celebrar atos de comércio decorrentes dessas atividades. A Sociedade é controlada pela Tractebel Energia S.A. (Tractebel Energia), que possui 99,99\% das quotas representativas do seu capital social.

O sistema de operação, utilizando biomassa como combustível, foi enquadrado como um Mecanismo de Desenvolvimento Limpo (MDL), de acordo com o Protocolo de Kyoto. Em abril de 2006, o Comitê Executivo do MDL, da Organização das Nações Unidas (ONU), concedeu o registro no MDL para a Unidade de Co-geração Lages pelo uso de resíduos de madeira como combustível, evitando dessa forma, a emissão de metano, um gás de efeito estufa, que seria gerado se tais resíduos continuassem a ser depositados inadequadamente e a se decompor no meio ambiente. 
Dessa forma, a usina está habilitada a gerar um montante de 220.000 toneladas de créditos de carbono (Certified Emission Reductions - CER) por ano para serem comercializados, dos quais $35 \%$ pertencem a Tractebel Energia, controladora da Sociedade, conforme Convênio de Mútua Cooperação pela Obtenção e Comercialização de Créditos de Carbono.

\subsection{UTILIZAÇÃO DOS CRÉDITOS DE CARBONO}

Neste item, buscou-se identificar os motivos pelos quais a empresa implantou o Mecanismo de Desenvolvimento Limpo através de uma entrevista semi-estruturada com o responsável pelo desenvolvimento do projeto.

Foi possível constatar através das perguntas um, dois e três do questionário, que não foi apenas um motivo que fez com que a empresa implantasse o projeto. $\mathrm{O}$ primeiro citado foi a possibilidade de uma receita adicional proveniente das vendas dos créditos de carbono, que em consequência disso, aumenta a taxa interna de retorno de um dado projeto. Além desse incremento na receita, o entrevistado cita a contribuição na imagem da empresa investidora e relata que geralmente os projetos com redução de emissão dos Gases do Efeito Estufa (GEE) contribuem para uma melhor aceitação dos órgãos ambientas, além de ajudar na relação com Bancos de Financiamento, com as ONG's e com as comunidades locais.

Fora citado também, a importância dos créditos de carbono para atrair investidores/acionistas e que as receitas auferidas nessas negociações são importantes em muitas empresas para financiarem seus projetos.

Ao ser questionado por quais medidas são adotadas pela Sociedade para a redução dos GEE's o entrevistado expõe que a mais significativa ação para essa questão está no investimento/implantação dos projetos de geração de energia elétrica, dos quais produzam energia sem emitir esses gases, como exemplos foram citados as usinas hidrelétricas enquadradas no MDL, as Pequenas Centrais Hidrelétricas - PCH's, as Usinas Eólicas, as Usinas a Biomassa, entre outros tipos.

Pode-se notar que os créditos de carbono contribuem e muito para a empresa. Com a obtenção destes créditos a organização passa a ter visibilidade e credibilidade com o público que gira ao seu redor, dês da comunidade em geral até seus acionistas. Conforme cita Rezende, Ribeiro e Dalmácio (2007) a exigência por responsabilidade social é uma realidade no mundo corporativo e cada vez mais se aprimora a busca por esses resultados. A controladora Tractebel Energia já se atenta a esses fatos e investe nesses fatores.

Barbieri (2006, apud REZENDE, RIBEIRO, DALMÁCIO, 2007) discorre que o mercado alterou sua configuração e gerou oportunidades e perspectivas para todos que já buscavam a eficiência ambiental, isso mostra que a visibilidade citada não é só apenas uma melhor imagem da empresa e sim um diferencial que a deixa mais bem quista.

\subsection{PROCESSO DE AQUISIÇÃO DOS CRÉDITOS DE CARBONO}

Para conhecer o processo de aquisição dos créditos de carbono foram realizadas as questões de quatro a sete, na qual a quarta questão tinha como objetivo saber qual a formação dos profissionais envolvidos com o projeto. Tivemos como resposta que ainda não foi designada uma classe profissional especifica para desenvolver esse projeto, portanto qualquer profissional está habilitado. Tipicamente, são encontrados engenheiros, advogados e administradores com especialização na área ambiental formulando os projetos de MDL.

A quinta questão foi direcionada a saber sobre a necessidade de consultoria e quando ela seria necessária. Obtemos como resposta que é necessário a utilização de consultoria em dois momentos, o primeiro é na elaboração completa do projeto e o segundo na organização do 
processo burocrático para registro do projeto na UNFCCC - United Nations Framework Convention on Climate Change.

Com o intuito de conhecer o caminho percorrido pela Lages Bioenergética para obtenção dos créditos, se fez a questão seis e sete, que questionavam quais os procedimentos, da criação do projeto até a aceitação e os órgãos envolvidos. Este foi relatado passo a passo, no qual é apresentado no quadro 4:

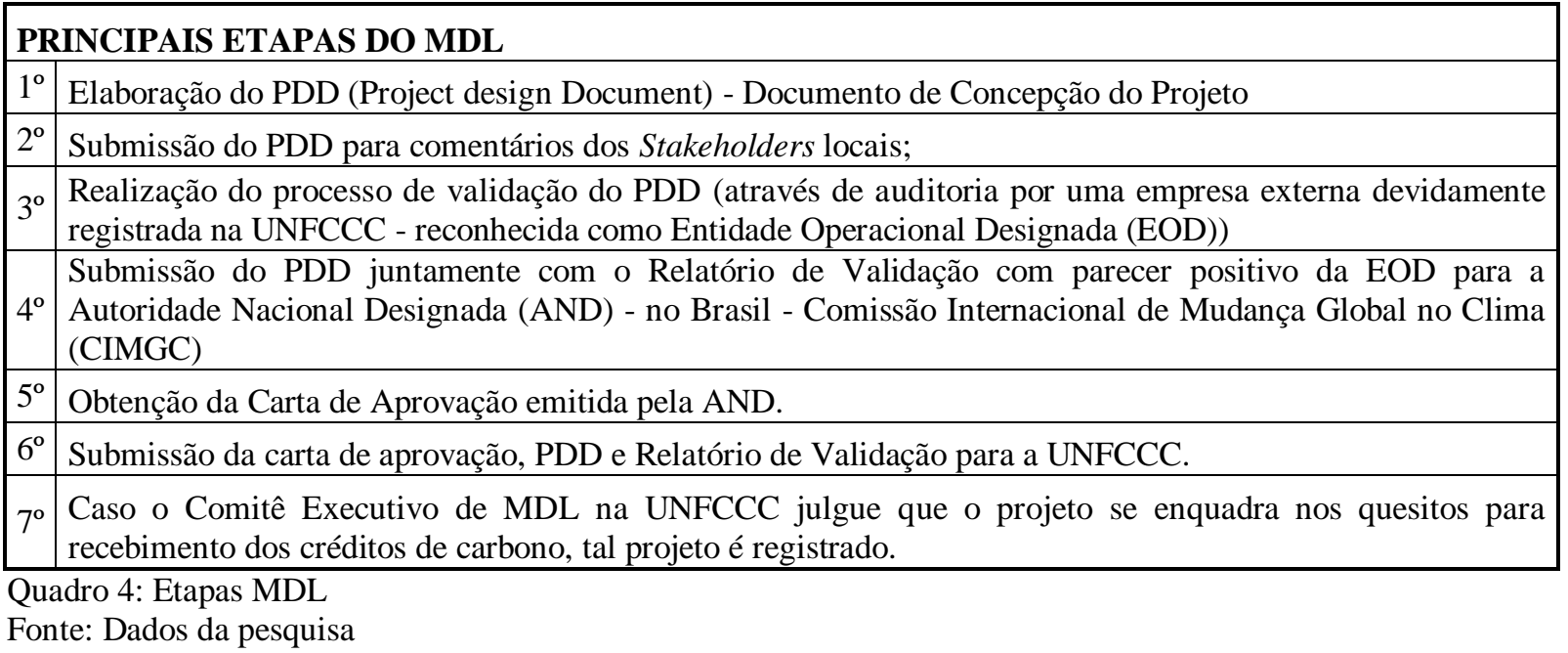

É importante ressaltar que o registro do projeto não possibilita a efetiva comercialização dos créditos de carbono. Para que isso ocorra, após o projeto entrar em operação, é necessária a contratação de uma nova auditoria externa (EOD) para realizar o processo de Verificação daquilo que foi efetivamente reduzido. Nessa etapa, o auditor confere os dados efetivamente medidos e o que de fato serve para contabilizar na redução de emissão real (no PDD enviado para registro constam apenas estimativas, as quais podem diferir dos valores efetivamente reduidos). Após a EOD emitir o Relatório de Verificação com parecer positivo, o mesmo deve ser submetido a UNFCCC com o pedido de emissão do Certificado de Redução de Emissões (CER - Certified Emission Reductions), o qual pode ser comercializado com países do Anexo I do Protocolo de Kyoto.

Em linhas gerais, pode-se notar que se confirma esses procedimentos descritos a cima com o que relata o quadro 1 de Maciel et al. (2009, p. 98 - 99). Ainda conclui-se, que é um processo burocrático longo e que envolve vários órgãos. Por isso sugere-se que muitas das potencias fontes de crédito de carbono do Brasil ainda não foram desenvolvidas, sendo que além de difícil concepção e a demora, faltam informações a estas.

\subsection{CONTABILIZAÇÃO EM DECORRÊNCIA DOS CRÉDITOS DE CARBONO}

Nesta subseção busca-se alcançar o terceiro objetivo específico que é demonstrar as contabilizações decorrentes da obtenção e negociação com o crédito de carbono. Após analisar as demonstrações e as explicações dadas pelos colaboradores da Lages Bioenergética Ltda., obtivemos algumas respostas.

Os custos decorrentes da obtenção do crédito são designados como despesas. Estas despesas são lançadas ao longo da negociação, quando elas ocorrem, respeitando o princípio da competência. As despesas ocorridas são: despesas de viagens, com auditoria, mão de obra própria entre outras. 
Esse tratamento das despesas está em consonância com os trabalhos de Pereira e Nossa (2005), pois eles explicam que estas despesas são pré-operacionais, e de acordo com a nova lei, as despesas pré-operacionais são como despesas do período. A receita gerada com essas negociações é lançada no momento em que se concretiza a venda dos créditos e ocorre o recebimento dos valores. A receita finda desta negociação é lançada na DRE na conta Outras Receitas, que engloba as Receitas Operacionais Bruta. Vale ressaltar que essa receita, com o crédito de carbono, tem isenção de PIS e CONFINS, pois são tratadas como exportação.

Para os créditos de carbonos aprovados e que ainda não foram vendidos, a Lages não demonstra no seu Balanço Patrimonial nenhuma provisão e nenhum estoque, justificam que os valores pertinentes a estes não são firmados e totalmente seguros para serem demonstrados no Balanço, mas mesmo assim são mencionados em notas explicativas. Os responsáveis pela contabilidade ainda explicam que poderíamos chamar os créditos de carbono não vendidos de certificados de "estoque" de crédito, pois se podem obter vários certificados e depois negociálos no mercado. Alguns autores como Pereira e Nossa (2005) citam que quando os créditos de carbono são aprovados, já se pode reconhecer o valor da receita dos mesmos, pois quando da "estocagem" o valor de mercado já pode ser determinado.

\section{CONCLUSAO E RECOMENDAÇÃO}

As emissões atmosféricas viraram uma preocupação mundial com o aumento das catástrofes naturais, vieram à tona temas como responsabilidade social e ambiental e desenvolvimento sustentável. Hoje as empresas usam como trunfo esses quesitos para se tornarem atrativas e mostrarem o quanto são responsáveis com o meio ambiente. Fazendo com que assim, a comunidade reconheça os seus incentivos.

Com essas preocupações a ONU promoveu o Protocolo de Quioto, que nele contempla o MDL. Essas negociações já ocorrem desde 2007, mas até hoje não há a definição contábil para essas transações. Com isso, o presente estudo teve por objetivo investigar a contabilização das negociações dos créditos de carbono na empresa Lages Bioenergética Ltda. Para alcançar o objetivo principal, surgiram 3 objetivos específicos que nortearam esta pesquisa: (a) identificar os motivos que trouxeram a empresa a ter créditos de carbono e quais seus benefícios; (b) identificar qual é o processo de aquisição dos Créditos de Carbono; e (c) demonstrar como é feito a contabilização de todos os fatos decorrentes da negociação com os créditos de carbono.

Para a obtenção das respostas destas indagações, foi construído um questionário com 7 questões aberta, tendo por base o referencial teórico que informa o tema. Estas 7 questões foram utilizadas para contemplação de uma entrevista semi-estruturada a qual foi realizada com o responsável pelos projetos de MDL na empresa Lages.

Foi possível perceber com as respostas que o processo de aquisição dos créditos de carbono é longo e burocrático, pois é necessário ter certificação junto a ONU e outros órgãos. A obtenção destes créditos traz muitos outros benefícios para empresa além da receita, como por exemplo, a facilidade de obtenção de financiamentos. Com o questionário também foi possível reconhecer os tratamentos contábeis para os créditos de carbono, que é reconhecido como outras receitas dentro do grupo de Receitas Operacionais.

Em linhas gerais, a pesquisa pôde mostrar como é reconhecida a receita com os créditos de carbono em uma empresa do ramo de energia elétrica. Fazendo assim, que esse tema seja divulgado e que as pessoas se atentem para esse novo mercado.

Partindo da limitação de regulamentação, sugere-se para futuras pesquisas: (i) que o mesmo estudo seja aplicado em outras empresas do mesmo ramo e de outros, para que se possa fazer 
o comparativo; e (ii) que se faça o estudo do direcionamento das receitas auferidas com o crédito de carbono.

\section{REFERENCIAS}

BARBIERI, K. S.; RIBEIRO, M. de S. Mercado de crédito de carbono: aspectos comerciais e contábeis. In: Congresso USP de Controladoria e Contabilidade, 7., 2007, São Paulo, Anais... São Paulo, 2007.

BM\&F. Disponível em: <http://www.bmf.com.br/bmfbovespa/pages/MBRE/faq.asp\#19>. Acesso em: 16 fev. 2012.

BUFONI, A. L.; FERREIRA, A. C. de S. Um debate sobre a contabilização de reduções certificadas de emissões. In: Congresso USP de Controladoria e Contabilidade, 10., 2010, São Paulo, Anais... São Paulo, 2010.

CENAMO, M. C. Mudanças Climáticas, o Protocolo de Quioto e o Mercado de Carbono . 2004. Disponível em:

〈http://www.cetesb.sp.gov.br/userfiles/file/mudancasclimaticas/proclima/file/publicacoes/rela torios_ipcc/portugues/cenamo_mc.pdf> Acesso em 16 FEV 2012.

CRUZ, S. R. S.; PAULINO, S. R. Projetos de mecanismo de desenvolvimento limpo (MDL) em aterros sanitários na cidade de São Paulo como instrumento de melhoria na gestão de resíduos sólidos urbanos. In: Encontro da Associação Nacional De Pós-Graduação e Pesquisa em Administração, 34., 2010, Rio de Janeiro, Anais... Rio de Janeiro, 2010.

FARIAS, L. G. Q. de. et al. Projeto de mecanismo de desenvolvimento limpo da Petrobras\Fafen: uma análise à luz das estratégias ambientais empresariais, das tecnologias ambientais e do desenvolvimento sustentável. In: Encontro da Associação Nacional De PósGraduação e Pesquisa em Administração, 34., 2010, Rio de Janeiro, Anais... Rio de Janeiro, 2010.

FERREIRA, A. C. de S. et al. Protocolo de Kyoto: uma abordagem contábil. In: Encontro Nacional sobre a Gestão Empresarial e Meio Ambiente, 9., 2007, Curitiba, Anais... Curitiba, 2007.

GIL, A. C. Como elaborar projetos de pesquisa. $4^{\text {a }}$ ed. Atlas: 2007.

LAKATOS, E. M.; MARCONI, M. de A. Fundamentos de metodologia científica. São Paulo: Atlas, 1991. 270 p.

MACIEL, C. V. et al. Crédito de carbono: comercialização e contabilização a partir de projetos de mecanismo de desenvolvimento limpo. Revista de Informação Contábil, Recife, v. 3, n. 1, p. 89-112, jan./mar. 2009.

PELEIAS, I. R. et al. Tratamento contábil dos projetos de crédito carbono no Brasil: um estudo exploratório. In: Encontro da Associação Nacional De Pós-Graduação e Pesquisa em Administração, 31., 2007, Rio de Janeiro, Anais... Rio de Janeiro, 2007. 
PEREIRA, M. M. A. M.; NOSSA, V. Crédito de carbono e reconhecimento da receita: o caso de uma operadora de aterro sanitário. In: Encontro da Associação Nacional De PósGraduação e Pesquisa em Administração, 29., 2005, Brasília, Anais... Brasília, 2005.

PEREIRA, M. M. A. M.; NOSSA, V.; NOSSA, S. N. Momento de reconhecimento da receita proveniente da venda de créditos de carbono: o caso de uma operadora de aterro sanitário no estado do Espírito Santo. Revista Contabilidade Vista \& Revista, Belo Horizonte, v. 20, n. 2, p. 99-133, abr./jun. 2009.

REZENDE, A. J.; RIBEIRO, M. S.; DALMÁCIO, F. Z. Uma análise multidimensional dos projetos brasileiros de MDL - mecanismo de desenvolvimento limpo. In: Encontro da Associação Nacional De Pós-Graduação e Pesquisa em Administração, 31., 2007, Rio de Janeiro, Anais... Rio de Janeiro, 2007.

RIBEIRO, M. de S. Os créditos de carbono e seus efeitos contábeis. In: Congresso da Associação Nacional dos Programas de Pós-Graduação em Ciências Contábeis, 1., 2007, Gramado, Anais... Gramado, 2007.

RICHARDSON, R. J. Pesquisa Social: métodos e técnicas. 3 ed. São Paulo: Atlas, 1999.

ROCHA, M. T. Aquecimento global e o mercado de carbono: uma aplicação do modelo Cert. Piracicaba, 2003. Tese (Doutorado) - Escola Superior de Agricultura "Luiz de Queiroz" da Universidade de São Paulo.

SCHMITT, A.; PEIXE, B. C. S. Contribuição de estudo exploratório sobre os principais projetos para viabilizar a comercialização dos créditos de carbono no Estado do Paraná. In: Congresso Brasileiro de Custos, 15., 2008, Curitiba, Anais... Curitiba, 2008.

SILVA JR, A. C. et al. Políticas públicas, tecnologias mais limpas e desenvolvimento sustentável: um estudo de projetos de mdl em parques eólicos no Brasil. In: Encontro da Associação Nacional De Pós-Graduação e Pesquisa em Administração, 34., 2010, Rio de Janeiro, Anais... Rio de Janeiro, 2010.

SOUZA, A. L. R et al. de. Análise dos aspectos contábeis no reconhecimento dos créditos de carbono em projetos de mdl no Brasil. In: Congresso Brasileiro de Custos, 17., 2010, Belo Horizonte, Anais... Belo Horizonte, 2010.

TASSO, C. C.; NASCIMENTO, E. Q. Protocolo de Quioto - Análise dos Aspectos Contábeis do Mercado de Carbono. In: $3^{\mathbf{0}}$ Simpósio FUCAPE de Produção Científica. 2005.

Disponível em:

<www.fucape.br/simposio/2/artigos/carla\%20tasso\%20e\%20edson\%20queiroz.pdf> Acesso em 16 FEV 2012.

VIEIRA, V. A. As tipologias, variações e características da pesquisa de marketing. Revista da FAE, Curitiba, v. 5, n. 1, p. 61-70, jan/abr. 2002.

YIN, R. K. Estudo de Caso: planejamento e métodos. Tradução de Daniel Grassi. 3. ed. Porto Alegre: Bookman, 2005. 